\title{
Cooperative apoptosis of coelomocytes of the holothurian Eupentacta fraudatrix and its modulation by dexamethasone
}

\author{
Olga A. Zaika, Lyudmila S. Dolmatova \\ Il’ichev Pacific Oceanological Institute, Far Eastern Branch, Russian Academy of Sciences, Vladivostok, Russia \\ Email: dolmatova@poi.dvo.ru
}

Received 27 June 2013; revised 27 July 2013; accepted 20 August 2013

Copyright (C) 2013 Olga A. Zaika, Lyudmila S. Dolmatova. This is an open access article distributed under the Creative Commons Attribution License, which permits unrestricted use, distribution, and reproduction in any medium, provided the original work is properly cited.

\section{ABSTRACT}

The capacities of phagocytes of subpopulation P1 (F) and morula cells (MC) of holothurian Eupentacta fraudatrix to modulate apoptosis of each other as well as cytokine-dependent mechanisms and hormonal regulation of these cells's interaction were studied. The 18-h treatment of $F$ with supernatants, obtained after centrifugation of MC preincubated for $3 \mathrm{~h}$ with phosphate buffered saline (PSB) at the temperature of $22^{\circ} \mathrm{C}$ (SMC3) resulted in a significant growth of apoptosis level. A 30-min incubation of $F$ with supernatants of MC, preincubated for 24 h (SMC24), on the contrary, reduced the apoptosis level and increased the level of interleukine-1 $\alpha$ (IL-1 $\alpha$ )-like substances, and 24-h incubation did not influence apoptosis and reduced level of IL-1 $\alpha$-like substances. Thus, proapoptotic effects of MC's supernatants in F inversely depended on time of their preincubation with PSB and directly on time of incubation with F. Additionally, this effect was opposite to variations in the level of IL-1 $\alpha$-like substances. The level of apoptosis declined after $30 \mathrm{~min}$ of incubation but elevated after $24 \mathrm{~h}$ at the inverse treatment of MC with supernatant, obtained after preincubation of F during $24 \mathrm{~h}$ (SF24). The level of IL-1 $\alpha$-like substances dropped after 30 min and insignificantly decreased after $24 \mathrm{~h}$. Hence, SF24 proapoptotic effect directly depended on time of incubation with MC and did not correspond to variations in the level of IL-1 $\alpha$-like substances. $100 \mu \mathrm{M}$ dexamethasone stimulated apoptosis in F and MC in an inverse time-dependent manner during 24-h preincubation, and supernatants of cell suspensions obtained after such preincubations, stimulated apoptosis and reduced the IL-1 $\alpha$-like substances level in target cells at both types of interaction. IL-1 $\alpha$-like substances are supposed to be mediators for MC's effects in F, but not for F's action on MC. In holothurians, steroid hormones apparently may participate in the regulation of the immune response and cell cooperation.

Keywords: Phagocytes; Morula Cells; Cell Cooperation; Dexamethasone; Apoptosis; Cytokines

\section{INTRODUCTION}

Over the last two decades, immunity of marine invertebrates has been intensively studied all over the world. This knowledge is especially urgent to understand evolution of the immune system, and to has a notion about the use of immune cells in modeling the immune response in lower animals, and it can also be applied for the invention of medicines and in environmental monitoring.

Echinoderms, being lower-organized animals, took a particular position among invertebrates_right at the root of Deuterostomia evolutional tree. Therefore, a number of factors of the innate immunity, typical for higher animals, manifest themselves completely in echinoderms too. Thus, in response to stimulation, immune cells of echinoderms produce reactive oxygen species (ROS), nitrogen oxide (NO), etc. [1]. Additionally, cytokine-like substances such as interleukin IL-1-, IL-2-, IL-6-, as well as tumor necrosis factor-like molecules, were found in echinoderms also [2,3]. Several types of circulatory cells named coelomocytes play the key role in immune response of echinoderms, of which phagocytes and morulalike cells are the most abundant $[1,4]$. Echinoderm phagocytes are functionally similar to macrophages of vertebrates, as they perform phagocytosis and encapsulation of foreign material [4,5]. Morula cells synthesize a number of humoral defense factors, including cytotoxic ones, and participate in encapsulation of foreign microorganisms, 
in wound healing and regeneration [4,6]. As is known, the immune response in vertebrates proceeds through the interaction of several types of immune cells, both as direct cell-to-cell contacts and via humoral factors such as the system of cytokines, excreted by cells into the environment $[7,8]$. As for echinoderms, data on similar interactions can be found only in few works [6] mostly due to the lack of information about the functional activity of certain types of phagocytes. Furthermore, there are no available data on probable regulatory mechanisms of the immune response.

Apoptosis (programmed cell death) is known to be one of important elements of the immune response in vertebrates. This is a physiological process, aimed to maintain homeostasis of the organisms, and it may intensify under some stress conditions [9]. As an interesting fact, a high level of background apoptosis, different for various types of immunocytes, is observed in freshly isolated coelomocytes of holothurians [10]. Therefore, the issue of a probable exchange with apoptotic signals between certain cells and the regulation of this exchange during the immune response in holothurians is of great importance.

The numerous studies of regulatory mechanisms of immune response in vertebrates revealed the important role of glucocorticoid hormones (GH), as the physiological inductors of apoptosis of immune cells in particular $[11,12]$. Hormones assumed probably the leading role in homeostasis regulation in lower animals-they are found in plants and animals at various levels of development, whereas in vertebrates, the system of hormonal regulation reaches the highest complexity and diversity [13].

Steroid molecules are observed also in all the phyla of invertebrates [14]. Among echinoderms, the steroid composition was studied most thoroughly in starfishes, which were found to have corticocosterods in their tissues [15]. As is stated in some of reports, GH may regulate functions in aquatic invertebrates. In particular, chronically given synthetic GH dexamethasone (Dex) inhibited the population growth of freshwater crustacean C. dubia [16]. Our previous data on concentration-dependent effect of dexamethasone on the apoptosis level in normal coelomocyte fractions of the holothurian E. fraudatrix [10] demonstrated that hormonal regulation of immune response, apparently, exists also in echinoderms, holothurians in particular.

Until recently, no adequate attention has been paid to issues of the immune response control in holothurians, neither the probability of cooperation of their immunocytes. Meanwhile many of holothurians are a highly demanded resource for the pharmaceutical industry [17] that entails the necessity of their cultivation. For this reason, the study of a probable exchange with apoptosismodulating signals between immune cells in holothu- rians and a control of this exchange is not only of theoretical, but also practical significance.

Holothurian Eupentacta fraudatrix inhabits coastal waters of the Sea of Japan. Earlier, two fractions of phagocytes P1 and P2, and a fraction, enriched with morula cells, have been isolated in them [18].

The aim of the study is to investigate the mechanisms of apoptosis-modulating interaction between phagocytes and morula cells as well as clarify the probability of their hormonal regulation in E. fraudatrix.

\section{MATERIALS AND METHODS}

\subsection{Animals}

E. fraudatrix individuals (4 - $6 \mathrm{~cm}$ in length) were collected in Peter the Great Bay in autumn and winter 2003-2004 and 2007-2008. Prior to experiments, they were kept in an aquarium with aerated seawater for 2 weeks.

\subsection{Coelomocyte Separation}

Coelomic fluid of each animal dissected was added into 10 -ml glass flasks with the following anticoagulant solution $(1: 1, \mathrm{v} / \mathrm{v}), 30 \mathrm{mM}$ ethylenediaminetetraacetic acid (EDTA), $31 \mathrm{~g} / \mathrm{l} \mathrm{NaCl}$, and $50 \mathrm{mM}$ Tris-HCl, pH 7.6 [4]. Combined fluid samples from 15 - 25 animals were applied to a ficoll-verographine discontinous gradient with the following proportions between ficoll-verographine and anticoagulant solution (v/v): Step 1, 1:0.4; Step 2, 1:1; and Step 3, 1:2 as described earlier [17]. The centrifugation was carried out at $300 \times \mathrm{g}$ for $15 \mathrm{~min}$ at $5^{\circ} \mathrm{C}$. The cells of phagocyte fraction P1 (F) were collected from the coelomic fluid sample/Step 3 interface, and cells of fraction enriched with morula cells (MC)-from Step 2/Step 1 interface. The cells were washed with phosphate-buffered saline (PBS) (36 g/l NaCl, $\mathrm{pH} 7.4$ ) and resuspended in medium 199 supplemented with $16.41 \mathrm{~g} / \mathrm{l}$ $\mathrm{NaCl}, 0.264 \mathrm{~g} / \mathrm{l} \mathrm{KCl}, 0.87 \mathrm{~g} / \mathrm{l} \mathrm{CaCl}{ }_{2}, 4.98 \mathrm{~g} / \mathrm{l} \mathrm{MgCl}_{2} \times$ $6 \mathrm{H}_{2} \mathrm{O}, 3.87 \mathrm{~g} / \mathrm{l} \mathrm{MgSO}_{4} \times 7 \mathrm{H}_{2} \mathrm{O}, 22.74 \mathrm{~g} / \mathrm{l}$ glycine, $0.1 \mathrm{~g} / \mathrm{l}$ glucose, $2.5 \mathrm{~g} / \mathrm{l}$ bovine serum albumin, and $50 \mathrm{mg} / \mathrm{l} \mathrm{so-}$ dium oxacillin as modification of method described by Odintsova [19]. Cells were counted in a Goryaev chamber.

\subsection{Experimental Design}

\subsubsection{Dexamethasone Effects on Cell Apoptosis}

The $1 \mathrm{ml}$ cell suspensions of each fraction were incubated in round-bottom plates $\left(5 \times 10^{5}-1 \times 10^{6}\right.$ cells/well $)$ at $22^{\circ} \mathrm{C}$ with PBS (control) or $100 \mu \mathrm{M}$ Dex (KRKA) in PBS. All incubations were performed in two parallel series. The samples were taken after $0,30 \mathrm{~min}, 18 \mathrm{~h}$ and $24 \mathrm{~h}$ of incubation.

A portion of cell suspensions was centrifuged at 1000 
$\times \mathrm{g}$ for $5 \mathrm{~min}$ at $5^{\circ} \mathrm{C}$ and the pellet was frozen and stored until DNA isolation.

\subsubsection{Cell Cooperation}

Scheme of the experiment is shown at Figure 1. The following variants of studies were performed:

1) The influence of morula cells on phagocytes. The cell suspension of MC $\left(10^{6}\right.$ cells $\left./ \mathrm{ml}\right)$ was incubated at $22^{\circ} \mathrm{C}$ for $3 \mathrm{~h}$ or $24 \mathrm{~h}$ (MC preincubation).

Thereafter, the cells were separated from incubation medium by centrifugation, and supernatants obtained in $3 \mathrm{~h}$ or $24 \mathrm{~h}$ (SMC3 or SMC24, respectively) were added $(1: 1, \mathrm{v} / \mathrm{v})$ to freshly isolated $\mathrm{F}\left(10^{6}\right.$ cells $\left./ \mathrm{ml}\right)$. Further incubation of $\mathrm{F}$ was performed at $22^{\circ} \mathrm{C}$ for $30 \mathrm{~min}$ or $24 \mathrm{~h}$.

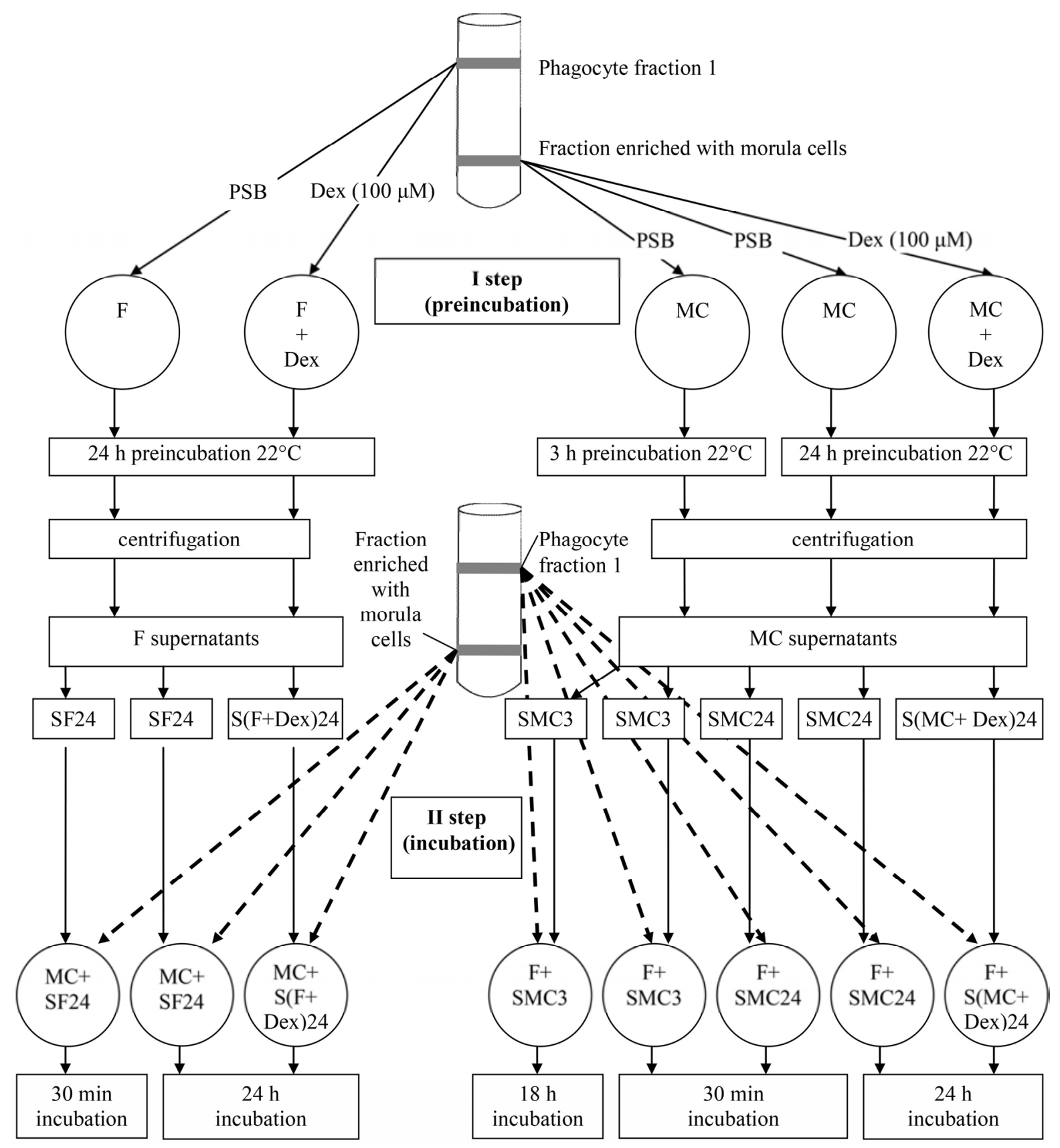

Figure 1. Design of experiments. F: cells of phagocyte 1 fraction; MC: cells of fraction enriched with morula cells; SF24: supernatants obtained after centrifugation of phagocytes preincubated with PSB for $24 \mathrm{~h}$; S(F + Dex)24: supernatants obtained after centrifugation of phagocytes preincubated with dexamethasone for $24 \mathrm{~h}$; SMC3 and SMC24: supernatants obtained after centrifugation of the suspension of the fraction enriched with morula cells preincubated with PSB for $3 \mathrm{~h}$ or 24 h, respectively; S(MC + Dex)24: supernatants obtained after centrifugation of the suspension of the fraction enriched with morula cells preincubated with Dex for $24 \mathrm{~h}$. 
2) The influence of phagocytes on morula cells. The suspension of $\mathrm{F}\left(10^{6} \mathrm{cells} / \mathrm{ml}\right)$ was incubated at $22^{\circ} \mathrm{C}$ for $24 \mathrm{~h}$ (F preincubation). After centrifugation, supernatant obtained (SF24) was added (1:1, v/v) to freshly isolated MC $\left(10^{6}\right.$ cells/ml). Further incubation of MC was performed at $22^{\circ} \mathrm{C}$ for $30 \mathrm{~min}$ or $24 \mathrm{~h}$.

3) The effect of Dex on cell cooperation. In some cases, $100 \mu \mathrm{M}$ Dex was added to cell suspensions of F or MC during their preincubation for $24 \mathrm{~h}$. Supernatants obtained $(\mathrm{S}(\mathrm{F}+\mathrm{Dex}) 24$ or S(MC + Dex)24, respectively) were added to corresponding target cells MC or F followed by $24 \mathrm{~h}$ incubation.

After all experiments were finished, a portion of each cell suspension was frozen in liquid nitrogen and stored at $-18^{\circ} \mathrm{C}$ until enzyme activity and IL- $1 \alpha$-like substances assays. Another portion of cell suspensions was centrifuged at $1000 \times \mathrm{g}$ for $5 \mathrm{~min}$ at $5^{\circ} \mathrm{C}$ and the pellet was frozen and stored until DNA isolation or fixed with $4 \%$ formalin until Hoechst 33342 staining.

\subsection{DNA Isolation}

DNA isolation was performed by the method described by Dolmatov et al. [18] with using $4 \mathrm{M}$ guanidine hydrochloride (Sigma-Aldrich) for deproteinization [20].

\subsection{Measurement of Apoptosis Level}

Apoptosis was estimated with using two methods: DNA agarose gel electrophoresis and Hoechst 33342 staining.

\subsubsection{DNA Electrophoresis}

DNA fragmentation was detected by agarose gel electrophoresis in Tris-borate buffer (pH 8.3) [21]. After electrophoresis, the gel was stained with ethidium bromide (Bio-Rad laboratories) and DNA fragments were visualized under UV light (240 nm).

\subsubsection{Hoechst 33342 Staining}

Cell pellets fixed with formalin were smeared and stained with Hoechst 33342 (Sigma-Aldrich) [22]. Apoptosis was calculated as percent content of bright blue fluorescent cells with using fluorescent microscope technique.

\subsection{IL-1 $\alpha$-Like Substances Assay}

The level of IL- $1 \alpha$-like substances was determined using kit for immune-enzyme analysis of human IL- $1 \alpha$ (Cytokin) according to manufacturer' instruction. Protein was quantified using Coomassie G-250 (Sigma-Aldrich) dye [23].

\subsection{Statistical Analysis}

To compare the groups, data (means $\pm \mathrm{SE}$ ) were analyzed using unpaired $t$ test. Means were considered sig- nificantly different when $\mathrm{p}<0.05$.

\section{RESULTS}

\subsection{Apoptosis Level in F and MC during Preincubation}

Incubation of $\mathrm{F}$ at $22^{\circ} \mathrm{C}$ during 30 min induced increase in apoptosis level by $42 \%$, as it was established with both DNA agarose gel electrophoresis (Figure 2(a)) and Hoechst 33342 staining (Figure 2(b)) methods. Further incubation for 18 - $24 \mathrm{~h}$ revealed a tendency to apoptosis level lowering compared to that in $30 \mathrm{~min}$. The addition of Dex, however, induced an increase in apoptosis level after 24 h (Figure 2(a)).

In MC (Figures 2(c) and (d)) the level of apoptosis also reached maximal value at $30 \mathrm{~min}$ of incubation, and then there was a tendency to its decline by $24 \mathrm{~h}$. Treatment of MC with Dex for $24 \mathrm{~h}$ induced the increase in apoptosis level compared to that in untreated cells (Figure 2(c)). (a)

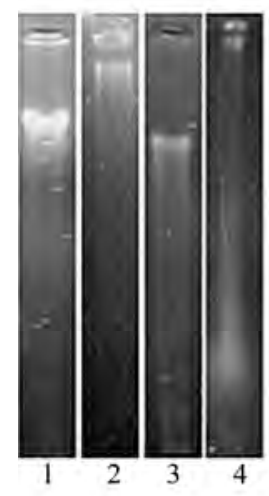

(c)

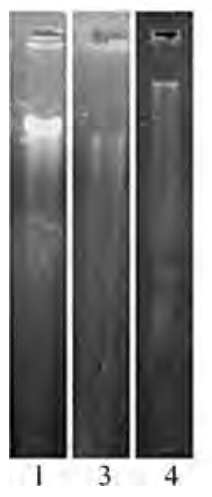

(b)

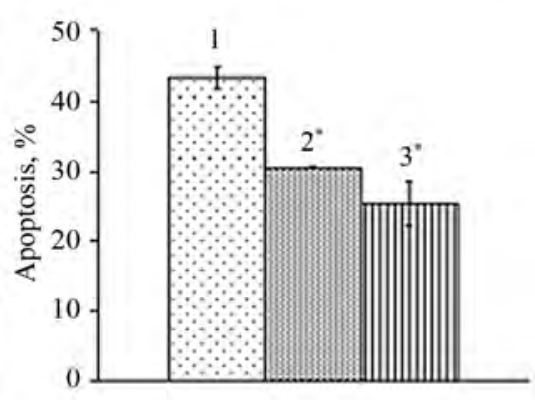

Figure 2. Apoptosis in cell fractions enriched with phagocytes type 1 ((a), (b)) and morula cells ((c), (d)) during preincubation at $22^{\circ} \mathrm{C}$ measured by methods using agarose gel electrophoresis ((a), (c)) and staining with Hoechst 33342 ((b), (d)). Experimental treatments: 1-PSB, preincubation for $30 \mathrm{~min}$; 2-PSB, preincubation for $18 \mathrm{~h}$; 3-PSB, preincubation for $24 \mathrm{~h}$; 4-Dex $(100 \mu \mathrm{M})$, preincubation for $24 \mathrm{~h} .{ }^{*} \mathrm{p}<0.05$ compared to the control (PSB). 


\subsection{The Influence of SMC and S(MC + Dex $) 24$ on Apoptosis in $F$}

To study the possible effects of MC on F, we treated F with supernatants obtained after centrifugation of MC being preincubated with PSB.

During 30 min-incubation of F with SMC24, DNA degradation was almost not observed (Figure 3(a)). The anti-apoptotic effect of supernatants of MC on F was confirmed with staining - the apoptosis level in $\mathrm{F}$ under the effect of SMC24 was 1.3 times as low (Figure 3(b)).

Meanwhile, a $24 \mathrm{~h}$ incubation of F with SMC24 did not result in significant variations in the apoptosis level in comparison with its level in control F incubated for 24 h. Thus, longer time of incubation of F and SMC24 caused a reduction of the anti-apoptotic effect of the latter. However, $24 \mathrm{~h}$ incubation of F and S(MC + Dex)24 led to the former's apoptosis increased by half over control (Figures 3(a) and (b)).

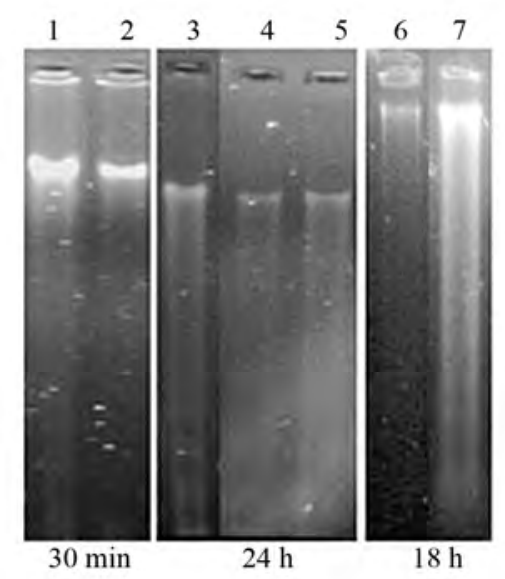

(a)

(b)

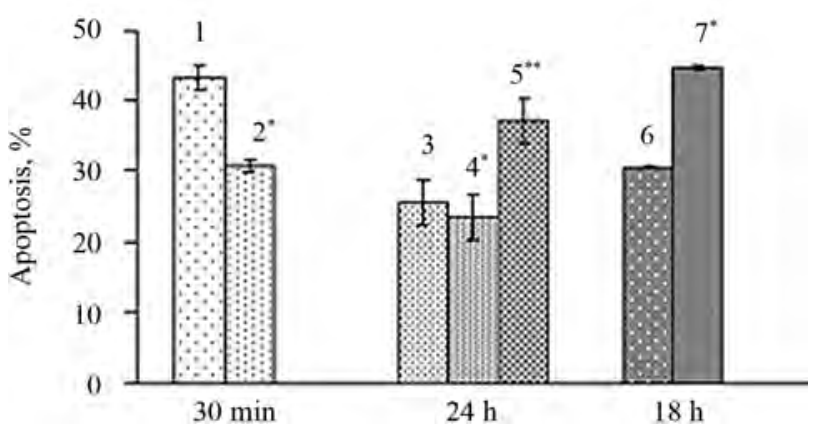

Figure 3. The influence of supernatants obtained after centrifugation of preincubated $\mathrm{MC}$ on the apoptosis level in $\mathrm{F}$, measurements were made by methods using agarose gel electrophoresis (a) and staining with Hoechst 33342 (b). Experimental treatments: 1, 3, 6-PSB (control); 2, 4-SMC24; 5-S(MC + Dex)24; 7-SMC3. Abscissa axis: time of incubation. ${ }^{*} \mathrm{p}<0.05$ compared to the control (PSB), ${ }^{* *} \mathrm{p}<0.05$ compared to that under treatment with SMC24.
The influence of duration of MC's pre-incubation on the effect of SMC was also studied. An addition of SMC3 to $\mathrm{F}$ followed by $18 \mathrm{~h}$ incubation resulted in the 1.4-time growth of the apoptosis level in $\mathrm{F}$. Thus, at a short time of pre-incubation of MC, its supernatant had a pro-apoptotic effect on F (Figures 3(a) and (b)).

The analysis of the temporal dependence of SMC effects showed that the apoptosis-inhibiting effect of SMC in $\mathrm{F}$ dropped with the increase of incubation time- the maximum inhibiting effect appeared after $30 \mathrm{~min}$ of incubation of F with SMC24. It is notable that a gradual decline of the apoptosis level also took place in the control $\mathrm{F}$ during $24 \mathrm{~h}$ of incubation.

In this study, $24 \mathrm{~h}$ incubation of F with S(MC + Dex)24 led to the former's apoptosis increased by half over control. It confirms the assumption that pro-apoptotic cleavage products accumulate in MC due to the increased apoptosis level in these cells, and S(MC + Dex)24, in turn, caused F's apoptosis to increase, compared with effect of SMC24 (apoptosis level in MC24 themselves was close to the control one).

\subsection{The Influence of SF and S(F + Dex $) 24$ on Apoptosis in MC}

When examining reverse effect of supernatants, obtained after $\mathrm{F}$ preincubation for $24 \mathrm{~h}$, on MC, decrease in DNA fragmentation, as compared to the control, was detected in as little as $30 \mathrm{~min}$ (Figure 4 (a)). The Hoechst 33342 staining indicated that apoptosis level had halved (Figure 4(b)).

Yet it was increasing, by comparison with control, during $24 \mathrm{~h}$ incubation of MC with SF24. Preincubation of $\mathrm{F}$ with Dex promoted further apoptosis increase in MC that were incubated with S(F + Dex)24 for $24 \mathrm{~h}$ (Figures 4(a) and (b)). Under effect of SF24 and S(F + Dex)24, apoptosis level increased by 1.9 and 2.8 times respectively, as compared to 24-h control. Thus, antiapoptotic effect of SF24 was followed by proapoptotic one, with $\mathrm{MC}$ and SF incubation period elongating, while $\mathrm{F}$ and Dex preincubation promoted the former's proapoptotic effect.

\subsection{IL-1 $\alpha$-Like Substances in F and MC during Their Humoral Interaction}

Both types of the cells proved to excrete IL- $1 \alpha$-like substances, and their level elevated in control cells insignificantly after the 24-h incubation as compared to the 30-min one-1.3 times in MC and 1.7 times in F (Figures 5(a) and (b)). However, when SMC24 was added to $\mathrm{F}$, for the first 30 minutes of incubation, the level of IL-1 $\alpha$-like substances in F increased 1.6 times, compared to the control, and dropped 2.2 times after $24 \mathrm{~h}$ (Figure 5(a)). The pre-incubation of MC with Dex caused sub- 


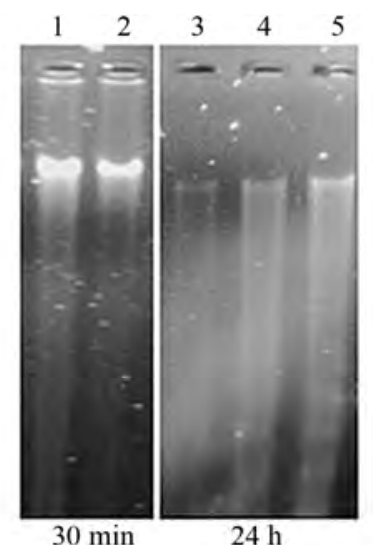

(a)

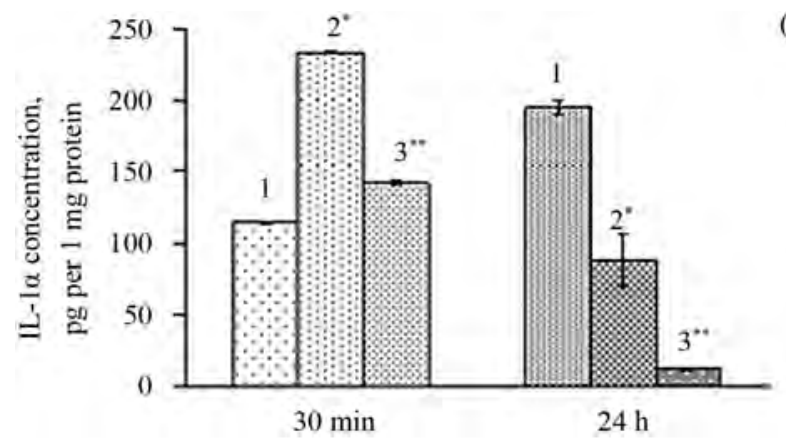

(b)

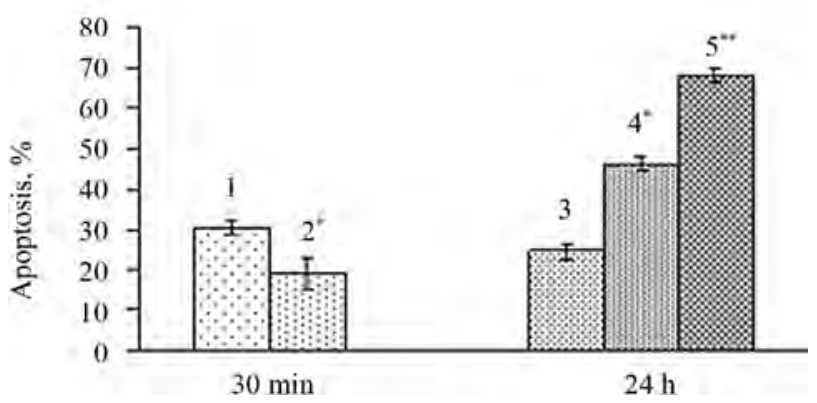

Figure 4. The effects of supernatants obtained after centrifugation of preincubated $\mathrm{F}$ on the apoptosis level in MC, measurements were made by methods using agarose gel electrophoresis (a) and staining with Hoechst 33342 (b). Experimental treatments: 1, 3-PSB (control); 2, 4-F24; 5-S(MC + Dex)24. Abscissa axis: time of incubation. ${ }^{*} \mathrm{p}<0.05$ compared to the control (PSB), ${ }^{* *} \mathrm{p}<0.05$ compared to that under treatment with SF24.

stances to return to the control level after $30 \mathrm{~min}$ and decreased even more as compared to the effect of SMC24 after $24 \mathrm{~h}$.

Incubation of MC with SF24 during 30 min resulted in the 2.4-time decrease of the level of IL-1 $\alpha$-like substances as compared to the control (Figure 5(b)).

If MC were incubated during 30 min with $\mathrm{S}(\mathrm{F}+\mathrm{Dex}) 24$, the level of IL-1 $\alpha$-like substances returned almost to the control one. After $24 \mathrm{~h}$ of incubation of MC both with SF24 and with S(F + Dex $) 24$, the observed decline of IL-1 $\alpha$-like substances' concentration reached $10 \%$ and $54 \%$, respectively, compared to the control.

\section{DISCUSSION}

Studying the probability of transmission of apoptosismodulating signals between $\mathrm{F}$ and $\mathrm{MC}$ and influences of Dex on the cell responses in E. fraudatrix, at the first stage, we examined the influences of preincubation condition and Dex on the cells studied. Earlier, we had re- (a)

(b)

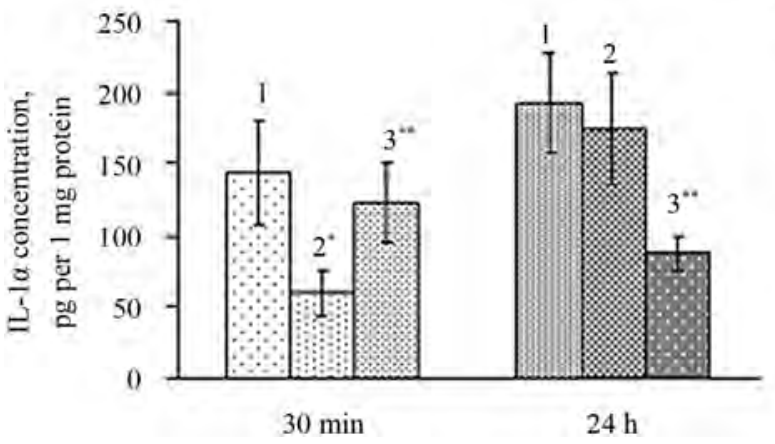

Figure 5. The level of IL-1 $\alpha$-like substances in F (a) treated with SMC24 and in MC (b) treated with SF24. Experimental treatments for (a): 1-PSB, control; 2-MC24; 3-S(MC + Dex)24. Experimental treatments for (b): 1-PSB, control; 2-SF24; 3$\mathrm{S}(\mathrm{F}+\mathrm{Dex}) 24$. Abscissa axis: time of incubation. ${ }^{*} \mathrm{p}<0.05$ compared to the control (PSB), ${ }^{* *} \mathrm{p}<0.05$ compared to that under treatment with supernatants obtained after centrifugation of the non-treated with Dex cells.

vealed the existence of pronounced spontaneous apoptosis in freshly isolated cells of MC but not F [10]. However, in both cell type studied, incubation for $30 \mathrm{~min}$ under stress temperature conditions $\left(22^{\circ} \mathrm{C}\right)$ caused significant increase in apoptosis level with further its decline by $24 \mathrm{~h}$. Dex stimulated apoptosis in both $\mathrm{F}$ and MC in 24 h compared to control. Such effect of Dex on holothurian immune cells corresponds to the results of numerous studies on vertebrates, which have shown that glucocorticoids promote apoptosis in mainly immature lymphocytes [12], neutrophiles [24], and macrophages [25]. However, further studies showed that SMC24 decreased apoptosis in F in reversed time-dependent manner. Similarly, MC supernatant's influence depended on the time of preincubation of MC, and SMC3 had even pro-apoptotic effect on F. Taking into account that a less pronounced apoptotic effect was found in $\mathrm{MC}$ preincubated for $24 \mathrm{~h}$ than that at $30 \mathrm{~min}$, we can assume that MC cells excrete some substances during incubation, having a modulating effect on F. Apoptosis-increasing effect of S(MC + Dex)24 in F confirms the assumption that pro-apoptotic cleavage products accumulate in MC due 
to the increased apoptosis level in these cells, and S(MC + Dex)24, in turn, causes F's apoptosis to increase. The obtained results evidence that the humoral products from $\mathrm{MC}$ are capable of modulating apoptosis in $\mathrm{F}$ in time-and concentration-dependent manner. Since the anti-apoptotic effect of SMC depended on the time of incubation with $\mathrm{F}$, decreasing in the course of incubation along with the reduction of apoptosis in $\mathrm{F}$, it can be supposed that these humoral substances exert a pronounced anti-apoptotic effect only at a significant level of apoptosis in the target cells.

Similarly, antiapoptotic effect of SF on MC had a reversed dependence on time of incubation with target cell, which changed even into proapoptotic one by $24 \mathrm{~h}$. The effect was also concentration-dependent, as apoptosis in MC increased when MC were treated with S(F + Dex)24. Given the fact that, after $24 \mathrm{~h}$ incubation of MC, their apoptosis levels were decreasing, compared to $30 \mathrm{~min}$ one, as mentioned above, it is possible to conclude that apoptosis-modulating effect of SF24 on MC depended on the apoptosis levels of the latter. Thus, F' humoral products may apparently regulate apoptosis in MC, and their effect depends on the level of apoptosis in target cell.

The mechanism of such dependencies of both SMC and SF effects on apoptosis level in target cells remains unclear, but it is probably complex and multifactorial like the most of apoptosis-modulating ones [26]. One of the key mechanisms of development of apoptosis under a stress is related to stimulation of the transcription factor p53 [27] through stimulation of ROS [28]. Besides, p53 can participate also in inhibition of the expression of anti-apoptotic genes [26]. However, according to the data in recent publications, p53 may exert also the anti-apoptotic effect by the feedback mechanism [29]. It seems probable that at the background of a high level of apoptosis in F in present work, humoral substances from MC, containing the pro-apoptotic factors, "switch on" the anti-apoptotic mechanism by the feedback scheme and induce its pro-apoptotic effect at the values of apoptosis close to initial ones.

Given the facts that maximum apoptosis activation in F during incubation takes place within first hours, and development of oxidative stress ("respiratory burst") precedes apoptosis of immunocytes [30], it is possible to suppose that MC3' products stimulate functional activity of the $\mathrm{F}$ within at least the first $18 \mathrm{~h}$, but not in $24 \mathrm{~h}$ of incubation.

In its turn, during 24-h incubation, when control MC's apoptosis level decreased, compared to that of $30 \mathrm{~min}$, SF24, by contrast, promoted apoptosis in MC. Since the role of some types of cells in the immune response in holothurians is studied insufficiently, physiological reasons for the effect like this cannot be determined for sure. However, as MC are considered to be analogues of mast cells of vertebrates [4], and facts on stimulation of mast cell activity (histamine release) with apoptosis-decreasing agents are known [31], apoptosis increasing effect of SF24 was, apparently, followed by inhibiting functional activity of MC. Apparently, cells of both types have time-dependent apoptosis-modulating effect on each other. In particular, MC can stimulate F's functional activity within the early period of incubation of cells (until 3 - 18 h). Later (in $24 \mathrm{~h}$ ), effects of both types of cells aimed at limitation of functional activity of each other. Such interaction confirms the existence of cell cooperation at the level of humoral products. Examples of a cooperation like these in vertebrates are the direct influence of mast cells on proliferation and differentiation of T-lymphocytes in vitro [32], as well as a variant of indirect cooperation when mast cells produce mediators that ensure T-lymphocyte's adhesion to fibroblasts [33]. Moreover, T-cells also have an influence on mast cells [34]. In particular, lymphocytes can initiate the synthesis of cytokines in mast cells [35].

According to the modern views, immune response of vertebrates is not limited to quick and efficient activation, but also includes adequate downregulation permitting to reduce very high costs of overshooting immune reactions [36]. But, while the limiting mechanisms, including cell interaction at the humoral level, particularly-immunomodulatory effect of anti-inflammatory cytokines [37], have been described for vertebrates, there is no such data on inveretebrates, with only description of morphological isolation of the cytotoxic immune effectors in the body cavity of Cimicidae [38]. Thus, our data are the first to point out to the possibility of time-dependent “+” and "-” interaction between immune cells of echinoderms, particularly in holothurians.

When considering the reasonability of this interaction in the pair F-MC, it seems probable that both types of cells have ability to stimulate functional activity at early phase of immune response but at the later phases they either do not stimulate or even reduce the activity of other cell type to ensure the expression of adequate immune response without damage to surrounding cells and tissues by ROS, production of which is directly related to functional activity of phagocytes, or by cytotoxic substances, resulted from MC activation. Hence, interactions of this kind provide a high degree of stability of immune system.

Additionally, data obtained points out to the fact that apoptosis in MC and F of holothurians can be regulated with glucocorticoids, similarly to immune cells of vertebrates, and pro-apoptotic signals induced by Dex can be transmitted both from MC to F, and from F to MC. Notably, that apoptosis-stimulating effect in $\mathrm{F}$, in contrast to MC, is rather related to stimulation of the F's activity and increase in ROS generation. Kraaij et al. [39] have 
shown that Dex could increase the ROS producing capacity of rat macrophages leading to suppression of $\mathrm{T}$ cell responses in a ROS-dependent manner. Similarly, in present work the stimulation of $\mathrm{F}$ by dexamethasone apparently could lead to suppression of MC. Taking into consideration that lymphocyte-like cells were also found in holothurians [40], we can not exclude ability of Dex to induce general immunosuppressive effects in holothurians via stimulation of ROS generation in $\mathrm{F}$.

In vertebrates, cytokines play the important role in humoral cooperation of immune cells, [7]. Further, we studied the variation in levels of IL- $1 \alpha$-like substances during cooperation of $\mathrm{F}$ and $\mathrm{MC}$.

The level of IL- $1 \alpha$-like substances in certain types of coelomocytes in echinoderms is not described in literature. Nevertheless it was shown that morula cells of some of marine organisms are the main producers of IL- $1 \alpha-$ like substances among coelomocytes [41]. Our data evidences a lack of significant difference between control cells studied during incubation. However, during 24-h incubation, there was a tendency to elevation of the levels of IL- $1 \alpha$-like substances in both types of cells. Such variations can indicate that IL- $1 \alpha$-like substances are excreted in response to stress conditions of preincubation of the cells. Nevertheless, the level of substances was significantly elevated after 30 min incubation of F with SMC24, but decreased in MC treated with SF24. In $24 \mathrm{~h}$ of incubation, SMC24, on the contrary, decreased the level of these substances in F, and SF24 elevated their level up to the control in MC.

IL- $1 \alpha$ is known to reduce apoptosis in cells of vertebrates [42]. It can be assumed that the increase of its level in F treated with SMC24 for $30 \mathrm{~min}$ as well as its decrease in $24 \mathrm{~h}$ are the reasons for inhibition or elevation of apoptosis level, respectively, in corresponding periods of time as it was described above. Additionally, a significant reduction in IL- $1 \alpha$-like substances' level in F under the treatment of S(MC + Dex)24 was shown. That corresponds to known data on the Dex suppressive effect on the IL-1 $\alpha$ synthesis in macrophages of vertebrates that is widely used in clinical practice [43]. The fact of simultaneously developing increase in apoptosis level and reduction in IL- $1 \alpha$-like substances' level in F under the effect of S(MC + Dex)24 supports the idea on primary role of cytokines in apoptosis-modulating effects of SMC in F. In addition, Dex was shown to play also an antiinflammatory role in E. fraudatrix, the same as those in vertebrates, for an excessive activation of IL- $1 \alpha$-like substances may result in damage to tissues of holothurian's organism.

On the contrary, the dynamics of variations in the level of apoptosis and IL- $1 \alpha$-like substances in MC under the effects of SF24 or S(F + Dex)24 indicates that in general there was no correlation between them; thus, a decrease in the IL-1 $\alpha$-like substances' level was found both within the first 30 minutes of incubation with SF24 (reduction of apoptosis) and after 24 h-with S(F + Dex)24 (increase in apoptosis). Apparently, cytokines do not play the main role in transmission of apoptotic signal from F to MC.

The data obtained show that there are different mechanisms of interaction between $\mathrm{F}$ and MC. This can be related to differences in functional activity of two types of cells. Various ways of apoptosis regulation in diverse types of cells are shown to exist also in vertebrates. e.g., neutrophils respond to signals, which are pro-apoptotic for other leukocytes, in the opposite way [30]. Moreover, neutrophils and mononuclear lymphocytes differently react to various stress stimuli that is observed particularly as multidirectional variations in activity of antioxidant enzymes [44]. This probably ensures their interaction at the immune response.

In present work, the effect of MC on F is apparently exerted just through the synthesis of IL- $1 \alpha$-like substances, $\mathrm{SF}$, on the contrary, possibly may have an effect on MC through any other molecules, e.g., ROS, generated by F. Earlier, the level of ROS in MC was shown to be much lower than that in F [45]. ROS are known to possess not only cytotoxic properties-they also can serve as secondary messengers, taking a part in regulation of the state of intracellular redox systems, activity of protein kinases, and regulation of cell reactions such as proliferation, differentiation, and apoptosis [46]. Particularly $\mathrm{H}_{2} \mathrm{O}_{2}$ activates a transcriptional factor NF-kB that results in induction of a number of pro-inflammatory cytokines in vertebrates $[47,48]$. At the same time, there are numerous data concerning $\mathrm{H}_{2} \mathrm{O}_{2}$ as a key signal in dexamethasone-induced apoptosis [49]. Further studies on oxidant-antioxidant balance of the cells during cooperation may clear the question on ROS part in this process.

\section{CONCLUSIONS}

The present studies revealed an interaction of cells of two fractions of coelomocytes of holothurians $-\mathrm{F}$ and $\mathrm{MC}$ - at the humoral level for the first time. F and MC had the apoptosis-stimulating or apoptosis-inhibiting effect on each other, depending on the level of functional activity of both effector and target cells. Similarly, at SMC's effect on F, apoptosis developed along with the decreasing level of IL- $1 \alpha$-like substances in F; at SF's effect on MC, vice versa, along with the growing level of IL-1 $\alpha$-like substances. This indicates different mechanisms of regulation of apoptosis level in two types of cells. Thus, we may suppose that IL- $1 \alpha$-like substances are the probable apoptosis-modulating humoral mediators of MC's effects in F, but not F's in MC. The revealed interaction between cells apparently ensures the expression of adequate immune response without dam- 
age to surrounding cells and tissues by ROS and other toxic substances.

Dex was shown to stimulate apoptosis in both type of cells, and the products being formed in the cells, preincubated with Dex, also stimulated apoptosis in target cells at both kinds of interaction studied. This indicates that Dex in holothurian's organism can produce general immunosuppressive effect, which is similar to that described for vertebrates. This implies a probability that steroids may participate in the regulation of the immune response in holothurians.

\section{REFERENCES}

[1] Kudryavtsev, I.V., Dyachkov, I.S., Kazakov, A.A., Kanaikin, D.P., Khazarova, A.D. and Polevschikov, A.V. (2005) Humoral reactions of innate immunity in the sea star Asterias rubens. Jurnal Evolutsionnoi Biokhimii Physiologii, 41, 23-28.

[2] Santiago, P., Roig-Lopez, J.L., Santiago, C. and GarciaArraras, J.E. (2000) Serum amyloid A protein in an echinoderm: Its primary structure and expression during intestinal regeneration in the sea cucumber Holothuria glaberrima. Journal of Experimental Zoology, 288, 335344.

doi:10.1002/1097-010X(20001215)288:4<335::AID-JEZ 6>3.0.CO;2-1

[3] Malagoli, D. (2010) Cytokine network in invertebrates: The very next phase of comparative immunology. Invertebrate Survival Journal, 7, 146-148.

[4] Chia, F. and Xing, J. (1996) Echinoderm coelomocytes. Zoological Studies, 35, 231-254.

[5] Isaeva, V.V. and Korenbaum, E.S. (1989). Defence functions of coelomocytes and immunity of echinoderms. Biologiya Morya, 6, 3-14.

[6] Arizza, V., Giaramita, F., Parrinello, D., Cammarata, M. and Parrinello N. (2007) Cell cooperation in coelomocyte cytotoxic activity of Paracentrotus lividus coelomocytes. Comparative Biochemistry and Physiology Part A: Molecular and Integrative Physiology, 147, 389-394. doi:10.1016/j.cbpa.2007.01.022

[7] Nguyen, H.X. and Tidball, J.G. (2002) Interactions between neutrophils and macrophages promote macrophage killing of rat muscle cells in vitro. The Journal of Physiology, 547, 125-132. doi:10.1113/jphysiol.2002.031450

[8] Costantini, C., et al. (2011) Human neutrophils interact with both 6-sulfo LacNAc + DC and NK cells to amplify NK-derived IFN \{gamma\}: Role of CD18, ICAM-1, and ICAM-3. Blood, 117, 1677-1686. doi:10.1182/blood-2010-06-287243

[9] Tsygan, V.N. (2004) Role of apoptosis in regulation of immune response. Obzory Klinicheskoy Pharmakologii Therapii, 3, 62-66.

[10] Dolmatova, L.S. and Zaika, O.A. (2010) Comparative effects of PGE2 on different types of immune cells in holothurian Eupentacta fraudatrix. In: Goodwin, G.M., Ed., Cell Biology Research Progress. Prostaglandins:
Biochemistry, Functions, Types and Roles, Nova Science Publishers, New York, 47-64.

[11] Greenstein, S., Ghias, K., Krett, N.L. and Rosen, T. (2002) Mechanisms of glucocorticorticoid-mediated apoptosis in hematological malignancies. Clinical Cancer Research, 8, 1681-1694.

[12] Herold, M.J., McPherson, K.J. and Reichardt, H.M. (2006) Glucocorticoids in T cell apoptosis and function. Cellular and Molecular Life Sciences, 63, 60-72. doi:10.1007/s00018-005-5390-y

[13] Chernysheva, M.P. (1995) Animal hormones: Introduction to physiological endocrinology. Glagol, Sankt-Peterburg.

[14] Lafont, R. and Mathieu, M. (2007) Steroids in aquatic invertebrates. Ecotoxicology, 16, 109-130. doi:10.1007/s10646-006-0113-1

[15] Gurst, J.E., Sheikh, Y.M. and Djerassi, C. (1973) Synthesis of corticosteroids from marine sources. Journal American Chemical Society, 95, 628-629. doi:10.1021/ja00783a076

[16] DellaGreca, M. (2004) Toxicity of prednisolone, dexamethasone and their photochemical derivatives on aquatic organisms. Chemosphere, 54, 629-637. doi:10.1016/j.chemosphere.2003.09.008

[17] Dolmatova, L.S. and Zaika, O.A. (2007) Apoptosis-modulating effect of prostaglandin E2 in coelomocytes of sea cucumber Eupentacta fraudatrix depends on antioxidant enzyme status of cells. Biology Bulletin of the Russian Academy of Sciences, 3, 221-229.

[18] Dolmatov, I.Yu., Dolmatova, L.S., Shitkova, O.A. and Kovaleva, A.L. (2004) Dexamethasone-induced apoptosis in phagocytes of holothurian Eupentacta fraudatrix. In: Heinzeller, T. and Nebelsick, J.H., Eds., Echinoderms, A.A. Balkema Publishers, Leiden, 105-119. doi:10.1201/9780203970881.ch20

[19] Odintsova, N.A. (2001) Bases of cultivation of marine invertebrate cells. Dalnauka, Vladivostok.

[20] Pramanick, D., Forstova, J. and Pivec, L. (1976) 4 M guanidine hydrochloride applied to the isolation of DNA from different sources. FEBS Letters, 62, 81-84. doi:10.1016/0014-5793(76)80021-X

[21] Gafurov, Yu.M. (1999) Deoxyribonucleases. Methods of investigation and properties. Dalnauka, Vladivostok.

[22] Pollack, A. and Ciancio, G. (1990) Cell cycle phase specific analysis of cell viability using Hoechst 33342 and propidium iodide after ethanol preservation. Methods in Cell Biology, 33, 19-24. doi:10.1016/S0091-679X(08)60508-7

[23] Bradford, M. (1976) A rapid and sensitive method for the quantitation of microgram quantities of protein utilizing the principle of protein-dye binding. Analytical Biochemistry, 72, 248-254. doi:10.1016/0003-2697(76)90527-3

[24] Fierro, I.M., Fidalgo, C., Canedo, R.M., Cunha, F.Q. and Ferreira, S.H. (1995) An increase in nitric oxide produced by rat peritoneal neutrophils is not involved in cell apoptosis. Mediators Inflammation, 4, 222-228. doi:10.1155/S0962935195000366

[25] Gromykhina, N.Yu. and Kozlov, V.A. (1996) Prostag- 
landin-dependent mechanisms of synthesis and action of immune control factors of macrophage and non-macrophage origin. Immunologiya, 5, 29-34.

[26] Shirokova, A.V. (2007) Apoptosis. Signal ways and changes in cell ion and water balances. Cytologia, 49, 385-394.

[27] Blagosklonny, M.V. (2002) P53: An ubiquitous target of anticancer drugs. International Journal of Cancer, 98, 161-166. doi:10.1002/ijc.10158

[28] Bragado, P., Armesilla, A., Silva, A. and Porras, A. (2007) Apoptosis by cisplatin requires p53 mediated p38 alpha MAPK activation through ROS generation. Apoptosis, 12, 1733-1742. doi:10.1007/s10495-007-0082-8

[29] Yang, M., Yuan, P., Li, P., Chen, Z., Chen, A., Li, S. and $\mathrm{Hu}, \mathrm{C}$. (2012) Interferon regulatory factor 4 binding protein is a novel p53 target gene and suppresses cisplatininduced apoptosis of breast cancer cells. Molecular Cancer, 11, 54. doi:10.1186/1476-4598-11-54

[30] Mayanskii, A.N., Mayanskii, N.A., Zaslavskaya, M.I., Pozdneev, N.M. and Pleskova, S.N. (1999) Apoptosis of neutrophils. Immunologiya, 6, 11-20.

[31] Torres, R.C., Batista, M.M., Pons, A.H., Silva, A.R., Cordeiro, R.S., Martins, M.A., Silva, P.M. and Carvalho, V.F. (2012) Activation of PPAR $\gamma$ by restores mast cell numbers and reactivity in alloxan-diabetic rats by reducing the systemic glucocorticoid levels. European Journal Pharmacology, 691, 261-267. doi:10.1016/j.ejphar.2012.06.010

[32] Nakano, N., et al. (2009) Notch signaling confers antigen-presenting cell functions on mast cells. Journal of Allergy and Clinical Immunology, 123, 74-81. doi:10.1016/j.jaci.2008.10.040

[33] Meng, H., et al. (1995) Mast cells induce T-cell adhesion to human fibroblasts by regulating intercellular adhesion molecule- 1 and vascular cell adhesion molecule- 1 expression. Journal of Investigative Dermatology, 105, 789796. doi:10.1111/1523-1747.ep12326075

[34] Valitutti, S. and Espinosa, E. (2010) Cognate interactions between mast cells and helper T lymphocytes. Self Nonself, 1, 114-122. doi:10.4161/self.1.2.11795

[35] Bhattacharjee, R., Xiang, W., Wang, Y., Zhang, X. and Billiar, T.R. (2012) cAMP prevents TNF-induced apoptosis through inhibiting DISC complex. Biochemical Biophysical Research Communications, 423, 85-90. doi:10.1016/j.bbrc.2012.05.087

[36] Dalpke, A., Heeg, K., Bartz, H. and Baetz, A. (2008) Regulation of innate immunity by suppressor of cytokine signaling (SOCS) proteins. Immunobiology, 213, 225235. doi:10.1016/j.imbio.2007.10.008

[37] Janeway, C.A. (2001) How the immune system protects the host from infection. Microbes Infection, 3, 11671171. doi:10.1016/S1286-4579(01)01477-0

[38] Siva-Jothy, M.T. (2006) Trauma, disease and collateral damage: Conflict in cimicids. Philosophical Transactions of the Royal Society B, Biological Sciences, 361, 269275. doi:10.1098/rstb.2005.1789
[39] Kraaij, M.D., der Kooij, S.W., Reinders, M.E., Koekkoek, K., Rabelink, T.J., van Kooten, C. and Gelderman, K.A. (2011) Dexamethasone increases ROS production and T cell suppressive capacity by anti-inflammatory macrophages. Molecular Immunology, 49, 549-557. doi:10.1016/j.molimm.2011.10.002

[40] Eliseykina, M.G. and Magarlamov, Yu. (2002) Morphology of coelomocytes of holothurians Apostichopus japonicus (Aspidochirota: Stichopodidae) and Cucumaria japonica (Dendrochirota: Cucumariidae). Biologia Morya, 28, 214-219.

[41] Ballarin, L., Franchini, A., Ottaviani, E. and Sabbadin, A. (2001) Morula cells as the major immunomodulatory hemocytes in ascidians: Evidences from the colonial species Botryllus schlosseri. Biological Bulletin, 201, 59-64. doi: $10.2307 / 1543526$

[42] McAllister, C.S., et al. (2012) TLR3, TRIF, and caspase 8 determine double-stranded RNA-induced epithelial cell death and survival in vivo. Immunology, 190, 418-427.

[43] Schmidt, S., Rainer, J., Pioner, C., Presul, E., Rimi, S. and Kofler, R. (2004) Glucocorticoid-induced apoptosis and glucocorticoid resistance: Molecular mechanisms and clinical relevance. Cell Death and Differentiation, 11, S45-S55. doi:10.1038/sj.cdd.4401456

[44] Tauler, P., Aguiló, A., Gimeno, I., Guix, P., Tur, J.A. and Pons, A. (2004) Different effects of exercise tests on the antioxidant enzyme activities in lymphocytes and neutrophils. Journal Nutritional Biochemistry, 15, 479-484. doi:10.1016/i.jnutbio.2004.03.002

[45] Corcoran, A. and Cotter, T.G. (2013) Redox regulation of protein kinases. FEBS Journal, 280, 1944-1965. doi:10.1111/febs.12224

[46] Dolmatova, L.S., Romashina, V.V. and Eliseykina, M.G. (2004) Antioxidant enzymatic activity of coelomocytes of the Far East sea cucumber Eupentacta fraudatrix. Journal of Evolutionary Biochemistry and Physiology, 40, 126135. doi:10.1023/B:JOEY.0000033803.35634.46

[47] Ren, D.L., Wang, H.K., Liu, J.Q., Zhang M.H. and Zhang, W.C. (2012) ROS-induced ZNF580 expression: A key role for $\mathrm{H}_{2} \mathrm{O}_{2} / \mathrm{NF}-\kappa \mathrm{B}$ signaling pathway in vascular endothelial inflammation. Molecular and Cellular Biochemistry, 359, 183-191. doi:10.1007/s11010-011-1013-0

[48] Padgett, L.E., Broniowska, K.A., Hansen, P.A., Corbett, J.A. and Tse, H.M. (2013) The role of reactive oxygen species and proinflammatory cytokines in type 1 diabetes pathogenesis. Annals of the New York Academy of Sciences, 1281, 16-35. doi:10.1111/j.1749-6632.2012.06826.x

[49] Jaramillo, M.C., Frye, J.B., Crapo, J.D., Briehl, M.M. and Tome, M.E. (2009) Increased manganese superoxide dismutase expression or treatment with a manganese porphyrin potentiates dexamethasone-induced apoptosis in lymphoma cells. Cancer Research, 69, 5450-5457. doi:10.1158/0008-5472.CAN-08-4031 